\title{
Tendencias en la investigación sobre las prácticas profesionales en educación superior: revisión sistemática desde la Psicología Organizacional y del Trabajo -POT
}

\author{
Trends in research about professional practices in higher \\ education: systematic review from Organizational and Work \\ Psychology-POT
}
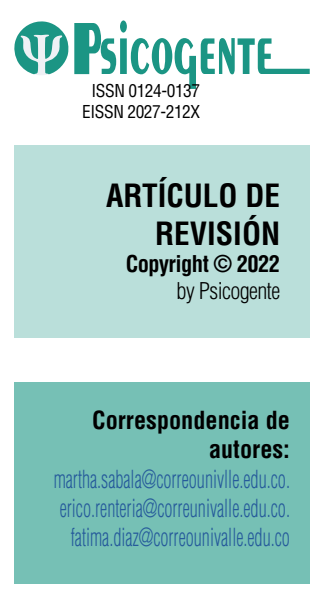

Recibido: 09-12-20 Publicado: 01-04-22 Aceptado: 24-01-22

\section{Tendências em pesquisa sobre estágio profissional no educação superior: revisão sistemática a partir da Psicologia Organizacional e do Trabalho -POT}

Martha Cecilia Sabala Moreno (ID - Erico Rentería Pérez (D)

Fátima Díaz Bambula iD

Universidad del Valle, Cali, Colombia

\section{Resumen}

Objetivo: Identificar y caracterizar las tendencias en investigación sobre las prácticas profesionales para contribuir al debate académico con relación a los problemas relevantes y actuales asociados a su desarrollo y como estrategia para la inserción laboral.

Método: El siguiente artículo presenta una revisión sistemática de alcance descriptivo donde se buscaron publicaciones entre los años 2000 a 2020, relacionadas con el tema de prácticas profesionales, en las bases de datos Redalyc, Scielo y Dialnet. Inicialmente del total de 308 estudios obtenidos se procedió a filtrar por su pertinencia y relevancia, se obtuvieron finalmente 64 artículos empíricos, sistematizados y abordados desde el análisis temático.

Resultados: Se encontró con relación a las competencias (21\%) y la formación profesional (11 \%) como más recurrentes, seguido de la identidad (5\%), percepción (5\%), vinculación universidad-empresa (5\%), significados (3\%), experiencias, empleabilidad (2\%), contextos $(2 \%)$, representaciones $(5 \%)$, condiciones laborales $(2 \%)$, salud mental $(2 \%)$, precarización $(2 \%)$, y finalmente, de menor recurrencia, memoria colectiva $(1 \%)$, currículo (1\%), bioética (1\%), agrupadas en 4 tendencias. Respecto a los diseños metodológicos, se encontró de mayor aplicación los cuantitativos (45\%), seguido de los cualitativos (39 \%) y los mixtos (16\%).

Conclusiones: La identificación, caracterización y análisis de lo que se ha investigado sobre el tema de las prácticas profesionales, permitió reconocer las tendencias surgidas en los estudios, el reconocimiento de los cuestionamientos de la relación entre la formación y aplicación profesional, como abordaje investigativo futuro para la Psicología organizacional y del trabajo, en un contexto de las transformaciones que ha tenido el mundo del trabajo y el impacto de este mismo en las prácticas profesionales como mecanismo para la inserción laboral.

Palabras clave: práctica profesional, tendencias, educación superior, Psicología Organizacional y de Trabajo.

Abstract

Objective: Identify and characterize the trends in research on internships in order to contribute to the academic debate regarding relevant and current problems associated with their development and as a strategy for labor market insertion.

Method: The following article presents a systematic review of descriptive scope where we searched for publications between 2000 and 2020, related to the subject of professional practices, in the databases

Cómo citar este artículo (APA):

Sabala Moreno, M. C., Rentería Pérez, E. \& Díaz Bambula, F. (2022). Tendencias en la investigación sobre las prácticas profesionales en educación superior: revisión sistemática desde la Psicología Organizacional y del Trabajo -POT . Psicogente 25(47), 1-25. https://doi.org/10.17081/psico.25.47.4835. 
Redalyc, Scielo and Dialnet. Initially, of the total of 308 studies obtained, 64 empirical articles, systematized and approached from the thematic analysis, were filtered for their pertinence and relevance.

Results: The following topics were found to be the most recurrent: competencies $(21 \%)$ and professional training (11\%), followed by identity (5\%), perception (5\%), university-business linkage (5\%), meanings (3\%), experiences, employability (2\%), contexts (2\%), representations (5\%), working conditions (2\%), mental health $(2 \%)$, precariousness $(2 \%)$, and finally, less frequently, collective memory $(1 \%)$, curriculum $(1 \%)$, bioethics (1\%), grouped in 4 tendencies. Regarding methodological designs, quantitative designs (45\%) were found to be more applicable, followed by qualitative (39\%) and mixed (16\%).

Conclusions: The identification, characterization, and analysis of what has been researched on the subject of internships, allowed the recognition of the trends that have emerged in the studies, the recognition of the questions on the relationship between formation and professional application, as a future research approach for Organizational and Work Psychology, in a context of transformations in the world of work and its impact on the internship as a mechanism of labor insertion.

Key Words: internship, trends, higher education, Organizational and Work Psychology.

Resumo

Objetivo: Identificar e caracterizar as tendências na pesquisa sobre estágios profissionais, a fim de contribuir para o debate acadêmico em relação aos problemas relevantes e atuais associados ao seu desenvolvimento e como estratégia de inserção laboral no mercado de trabalho

Métodos: $\mathrm{O}$ artigo seguinte apresenta uma revisão sistemática do escopo descritivo onde as publicações entre os anos 2000 a 2020, relacionadas ao tema sobre estágios profissionais, foram pesquisadas nas bases de dados Redalyc, Scielo e Dialnet. Inicialmente, do total de 308 estudos obtidos, procedemos à filtragem por sua relevância e, finalmente, 64 artigos empíricos foram obtidos, sistematizados e abordados a partir da análise temática.

Resultados: Foi encontrado em relação aos temas: competências (21 \%) e formação profissional (11 \%) como os mais recorrentes, seguidos pela identidade (5\%), percepção $(5 \%)$, vinculação universidade-empresa $(5 \%)$, significados $(3 \%)$, experiências, empregabilidade $(2 \%)$, contextos $(2 \%)$, representações $(5 \%)$ condições de trabalho $(2 \%)$, saúde mental $(2 \%)$, precariedade $(2 \%)$ e, finalmente, de menor recorrência, memória coletiva (1\%), currículo (1\%), bioética (1\%), agrupados em 4 tendências. Quanto aos desenhos metodológicos, quantitativos (45\%), seguidos pelos qualitativos (39\%) e mistos (16\%).

Conclusões: A identificação, caracterização e análise do que foi pesquisado sobre o tema do estágios profissionais, permitiu o reconhecimento das tendências que surgiram nos estudos, o reconhecimento do questionamento da relação entre treinamento e aplicação profissional, como uma abordagem de pesquisa futura para a Psicologia Organizacional e do Trabalho, em um contexto de transformações no mundo do trabalho e seu impacto no processo de práticas como mecanismo de inserção laboral.

Palavras-chave: estágio, tendencias, educação superior, Psicologia Organizacional e do Trabalho.

\section{INTRODUCCIÓN}

Históricamente el conocimiento se ha concebido como un generador de desarrollo y principalmente transformador social, la capacidad de aprender es central y aunque puede existir diferentes contextos y de distintas maneras, hoy el carácter diferenciador involucra una serie de actores cuya dinámica incorpora organizaciones, instituciones y a nivel profesional las universidades como espacios para la formación en educación superior y que, como parte del sistema educativo enfrentan demandas en función al sistema productivo. Aunque la universidad no forma exclusivamente para el mercado de trabajo (Rentería y Malvezzi, 2008) sí hay un aspecto central es el énfasis de su papel como centros de cualificación profesional que deben facilitar la empleabilidad de los profesionales (Rentería 2007, 2008), planteándole innovaciones organizacionales que le brinden a la formación profesional un carácter diferenciador para cualificar lo aprendido en las prácticas a través de la experiencia 
y ejercicio aplicado que permita inclusive anticipar la evolución de las necesidades del mercado laboral (Aguilar y Rentería, 2017), situaciones que no han sido indiferentes para el campo de la psicología organizacional y del trabajo, donde se crean nuevos retos para su comprensión e investigación.

\subsection{La formación profesional}

La formación profesional es un terreno fundamental particularmente para la educación superior, no solo porque tiene que ver con el desarrollo de conocimientos y habilidades y su aplicabilidad en contextos particulares con problemáticas específicas, sino también con el vínculo entre el estudio y el trabajo que permite el contacto con el objeto y modos de actuación de la profesión en el contexto en que se inserta. Esta articulación de experiencias cercanas al mundo productivo se ha concretado a través de la práctica profesional, que como concepto se ha planteado desde diferentes enfoques y perspectivas (Campillo, Sáez y Del Cerro, 2012). Desde la perspectiva psicosocial, las prácticas profesionales se han concebido como tránsito de la teoría a la práctica en ámbitos como las organizaciones y/o instituciones, constituyéndose en espacios de configuración de la organización y construcción de la identidad profesional del individuo vinculada a las organizaciones a las que pertenece (Alcover, 2003). Desde el contexto sociocultural, se enfatiza como curso de vida, la transición relacionada con el proceso de inserción laboral (Casal, 1997; Garrido y Requena, 1996; Martín, 2003), donde los escenarios posibilitan la interacción entre educación y el mundo laboral (Echeverri, 2018).

Desde otra perspectiva, la ontológica, se puede considerar como la manera en que un complejo sistema social incide de forma directa sobre las acciones del sujeto, que es capaz de aprehender, dinamizar e incluso impactar, para hacerle frente a dicho sistema, con sus propios recursos (Delgado, 2018). Desde el panorama de desarrollo humano, se conciben como una experiencia intersubjetiva de socialización profesional guiada por demandas particulares emergentes de ámbitos como los entornos socioeducativos donde quedan plasmados los mecanismos relacionados con la reproducción y la recreación. (Gimeno, 1991).

Desde la perspectiva curricular, las prácticas profesionales se abordan considerando dos grandes enfoques: el clásico- tradicional y el tecnológico-instruccional. La formación está constituida por una serie de reglas y principios establecidos en los planes de estudio que posibilitan que los estudiantes desarrollen competencias (Díaz, 2002). 
La interfase entre la formación con los procesos de socialización está ligada a la academia y particularmente al mundo del trabajo lo que exige articular los requerimientos al tipo de "profesional" que demanda el mercado de trabajo (Rentería y Malvezzi, 2008). En consecuencia a estas presiones resultado del desarrollo económico, tecnológico a nivel mundial y en un mundo globalizado, para la educación y los dispositivos de formación, la empleabilidad se concibe como encargo social a las instituciones de educación (Botero, Rentería y Malvezzi, 2020), que son obligadas a responder a las necesidades del contexto y a desafíos como la articulación de los jóvenes a los espacios de participación en el mundo laboral por medio de mecanismos de inserción como lo son las prácticas profesionales.

Con relación a lo anterior, las prácticas han propiciado un marco legislativo que regula la experiencia directa con el contexto (Adamini, 2012) en el que se ha necesitado un esquema para el proceso de aprendizaje que permita la fluidez y circulación del conocimiento de manera correspondiente entre las figuras empleadoras y los empleados en proyección, como es el caso Practicum (Zabalza, 2011). Esta manera de articular el campo del trabajo con el campo de la educación se ha concentrado en incorporar herramientas de carácter formativo para la inserción laboral de estudiantes, que se ha enfatizado en el empleo estable, como se evidencia a partir de los estudios que integran la revisión sistemática donde en su gran mayoría se incluye como referente prioritario el empleo pleno tradicional como condición de preparación de los individuos para hacer parte de los mercados de trabajo tradicional.

Teniendo en cuenta la intensificación del papel de las prácticas profesionales, se vuelve relevante ampliar la comprensión de este proceso a partir de diferentes producciones académicas, desde sus perspectivas teórico-metodológicas, contextos de desarrollo, dando lugar a la pregunta de revisión: ¿Cuáles son las tendencias en investigación sobre prácticas profesionales?

Para su lectura, se enfatiza una determinada tendencia y caracteriza en general, la relación entre la formación profesional y el mercado de trabajo desde la perspectiva de la psicologia organizacional y del trabajo-POT.

\section{MÉTODO}

\subsection{Diseño}

Se realizó una revisión sistemática (Gough, Oliver y Thomas, 2012), la cual permitió mapear, identificar, describir y evaluar de manera crítica los informes de artículos empíricos de investigaciones sobre las prácticas profesionales. 


\subsection{Procedimiento}

La revisión sistemática se realizó teniendo en cuenta una ruta de trabajo integrada por dos protocolos (de búsqueda y de normas de revisión) (Barbosa, Barbosa y Rodríguez, 2013). La primera búsqueda se estructuró teniendo en cuenta elementos como los recursos de información, estrategias de búsqueda de las palabras clave como: práctica profesional, prácticas profesionales, pasantía, pasantías, práctica supervisada, prácticas externas y practicum, estas búsquedas fueron filtradas en un rango de años que comprendió desde el 2000 hasta el 2020 en las bases de alcance Iberoamericano como; Redalyc, Scielo y Dialnet. El segundo protocolo implementado, fue el de revisión de la información con criterios de inclusión como, artículos empíricos que tuvieran en sus títulos, descriptores o abstract, las palabras claves establecidas y para los criterios de exclusión se consideraron artículos de revisión literaria, artículos reflexivos, artículos de revisión normativa, artículos de sistematización de experiencias, y artículos cuya investigación se hayan realizado a partir de ámbitos que el nivel profesional haya sido técnico y tecnológico, y además se tuvo en cuenta aspectos como la pertinencia con relación a los objetivos de la revisión sistemática.

Las búsquedas en las bases de datos arrojaron un total de 308 artículos relacionados con el tema de las prácticas profesionales, una vez obtenidos, se procedió a filtrar estos artículos en la lógica de la pertinencia y relación con el tema, quedando 215; posteriormente se excluyeron los documentos duplicados, y a los 188 artículos se le aplicaron los criterios de exclusión nuevamente, arrojando un total de 97 artículos de carácter empírico relacionados con el tema, que a partir de un proceso de síntesis para evaluar su calidad y pertinencia (Gough, Oliver y Thomas, 2012), con criterios como relevancia con el tema de la revisión sistemática, contribución para responder la pregunta de investigación y aporte para el alcance de los objetivos, además de los soportes teóricos, claridad metodológica, resultados y solidez en la estructura del artículo, resultaron finalmente 64 documentos.

\subsection{Análisis de la información}

Los 64 artículos elegidos fueron organizados y codificados obteniendo índices de representatividad en porcentajes para su posterior interpretación; en cuanto al contenido de los artículos, se realizó un análisis temático que permitió hacer una descripción y caracterización de orden cualitativo de los datos obtenidos en los artículos (Braun y Clarke, 2006). 


\subsection{Resultados}

Aquí se presentan los resultados correspondientes a la distribución porcentual acorde con el país donde se desarrolla la investigación, el área de conocimiento de predominio para sus abordajes, además del diseño metodológico, los instrumentos más utilizados y población más estudiada como lo evidencia la Tabla 1.

Tabla 1.

Estudios según país, diseño metodológico, población, área de conocimiento y población

\begin{tabular}{|c|c|c|}
\hline PAÍS & DISEÑO METODOLÓGICO & POBLACIÓN \\
\hline $\begin{array}{l}\text { Del total de los } 64 \text { artículos de la revisión sistemática } \\
\text { con relación a la práctica profesional cumplieron con } \\
\text { los criterios expuestos en la síntesis. Con respecto } \\
\text { a los años de mayor publicación fue entre el } 2010 \\
\text { a 2017, encontrándose un total de } 41 \text { artículos, y } \\
\text { para el periodo comprendido desde el año } 2000 \\
\text { al 2005, menor documentos, aproximadamente } \\
3 \text { artículos con el tema y los criterios de inclusión } \\
\text { propuestos. Desde los países, el mayor número de } \\
\text { investigaciones, España con una representatividad del } \\
28 \% \text {, seguido de Colombia con un } 16 \% \text {, Argentina y } \\
\text { México con un } 13 \% \text {, Chile con un } 9 \% \text {, Brasil con un } \\
8 \% \text {, Venezuela con un } 5 \% \text {, Ecuador con un } 3 \% \text {, y en } \\
\text { menor índice de representatividad están países como } \\
\text { Panamá, y Perú, Costa Rica y Cuba con un } 2 \% \text {. }\end{array}$ & $\begin{array}{l}\text { Respecto al Método de las investigacio- } \\
\text { nes sobre las prácticas profesionales se } \\
\text { encontró que el } 45 \% \text {, corresponden al } \\
\text { corte cuantitativo, el } 39 \% \text { cualitativo } \\
\text { y el } 16 \% \text { corte mixto. Con relación a } \\
\text { los instrumentos de recolección, se } \\
\text { encontró estudios que utilizan más } \\
\text { de un instrumento, encontrándose el } \\
26 \% \text { de los instrumentos aplicados } \\
\text { fueron entrevistas y encuesta, un } 17 \% \text {, } \\
\text { cuestionarios, un } 13 \% \text {, la revisión } \\
\text { documental, } 6 \% \text { la observación y } \\
\text { finalmente } 4 \% \text {, como instrumentos de } \\
\text { menos uso las escalas estandarizadas y } \\
\text { los grupos focales. }\end{array}$ & $\begin{array}{l}\text { En cuanto a la población abordada en } \\
\text { las investigaciones, con mayor repre- } \\
\text { sentatividad de un } 57 \% \text { los estudiantes } \\
\text { (practicantes/ pasantes), por prefe- } \\
\text { rencia para acercarse a los fenómenos } \\
\text { y temáticas de interés, seguido de un } \\
16 \% \text {, los supervisores internos, } 11 \% \text {, } \\
\text { egresados, } 7 \% \text {, población del sector } \\
\text { productivo y empleadores, con un } 7 \% \text {, } \\
\text { los supervisores externos y finalmente, } \\
\text { con un } 2 \% \text { representado en inves- } \\
\text { tigaciones que se interesaron por la } \\
\text { información contenida en los proyectos } \\
\text { de práctica profesional y los informes. }\end{array}$ \\
\hline & \multicolumn{2}{|c|}{ TEMÁTICA } \\
\hline $\begin{array}{c}\text { Con relación al área de conocimiento desde donde } \\
\text { abordaron las investigaciones, predomina con un } \\
42 \% \text {, las ciencias de la educación seguido del } 24 \% \\
\text { ciencias sociales y humanas, un } 14 \% \text {, las ciencias de } \\
\text { la salud, } 12 \% \text {, las ciencias económicas y administrati- } \\
\text { vas y áreas de menor abordaje con un } 5 \% \text { inge- } \\
\text { niería y afines y con un } 3 \% \text { matemáticas y ciencias } \\
\text { naturales. }\end{array}$ & \multicolumn{2}{|c|}{$\begin{array}{l}\text { Los temas más recurrentes o de mayor representatividad son, con un } 21 \% \text {, las } \\
\text { competencias seguido con un } 11 \% \text {, la formación (profesional, íntegra práctica), } \\
\text { con un } 5 \% \text {, los temas de identidad, percepción, vinculación educación (universi- } \\
\text { dad- empresa), el } 4 \% \text {, inserción laboral, desempeño, aprendizaje y supervisión, y } \\
\text { temas de menor recurrencia con un } 3 \% \text {, significados, experiencias, y con un } 2 \% \\
\text { empleabilidad, contexto, representaciones, condiciones, salud mental, precari- } \\
\text { zación laboral, y por último el } 1 \% \text { en los temas de memoria colectiva, currículo y } \\
\text { bioética. Es pertinente mencionar que varios artículos abordaron más de un tema } \\
\text { en su desarrollo, por ejemplo, era común encontrar la relación entre el tema de } \\
\text { competencias y formación, entre inserción laboral y empleabilidad, entre percep- } \\
\text { ción y representaciones, memoria colectiva y precarización, entre otros, como se } \\
\text { evidencia en la Tabla. } 2 \text {. }\end{array}$} \\
\hline
\end{tabular}

De acuerdo con los resultados en la Tabla 1, se denotan aspectos de énfasis relacionados con las investigaciones como; temáticamente de mayor aplicación se encuentran las competencias (21\%) y con menor representatividad la inserción laboral (4 \%) y la empleabilidad (2 \%), llamando la atención con respecto al aporte sobre la relación formación profesional y empleabilidad. Con respecto a los participantes más indagados son los estudiantes en calidad de practicantes o pasantes. 
A continuación, en la Tabla 2, se sintetiza la información concerniente a los 64 estudios seleccionados para la revisión sistemática iniciando desde el contexto Iberoamericano con el país de mayor número de investigaciones, España (28\%), continuando con los autores, temáticas, objetivo, diseño metodológico, instrumento y población.

Tabla 2.

País de origen, autores, temáticas, objetivo, diseño metodológico, instrumento y población.

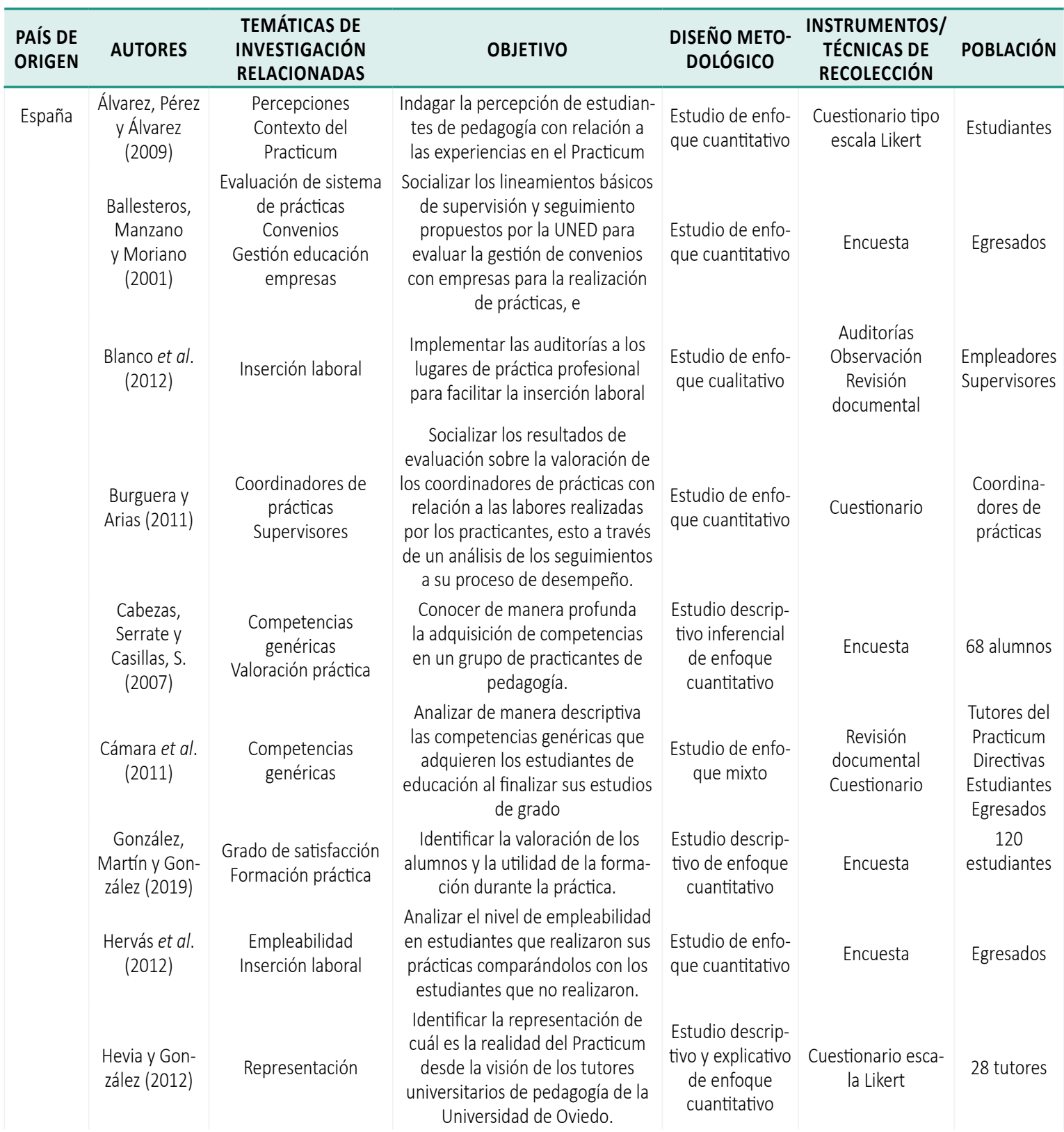




\begin{tabular}{|c|c|c|c|c|c|}
\hline $\begin{array}{l}\text { Mareque, } \\
\text { Prada y Pino } \\
\text { (2018) }\end{array}$ & $\begin{array}{l}\text { Percepciones } \\
\text { Competencias } \\
\text { profesionales }\end{array}$ & $\begin{array}{l}\text { Analizar las percepciones de los } \\
\text { estudiantes universitarios y los } \\
\text { empleadores sobre la adquisición } \\
\text { de competencias en las prácticas } \\
\text { la carrera de turismo }\end{array}$ & $\begin{array}{l}\text { Estudio de enfo- } \\
\text { que cuantitativo }\end{array}$ & $\begin{array}{l}\text { Escala Likert } \\
\text { para medir } \\
\text { competencias }\end{array}$ & $\begin{array}{l}\text { Emplea- } \\
\text { dores } \\
\text { practicantes }\end{array}$ \\
\hline $\begin{array}{l}\text { Mayorga, } \\
\text { et al. (2017) }\end{array}$ & $\begin{array}{l}\text { Grado de satisfacción } \\
\text { Utilidad profesional }\end{array}$ & $\begin{array}{c}\text { Conocer el grado de satisfacción } \\
\text { de con relación al Practicum en } \\
\text { egresados de una facultad de } \\
\text { educación }\end{array}$ & $\begin{array}{l}\text { Estudio descrip- } \\
\text { tivo de enfoque } \\
\text { cuantitativo }\end{array}$ & Encuesta & $\begin{array}{c}261 \\
\text { egresados }\end{array}$ \\
\hline $\begin{array}{l}\text { Montejano } \\
\text { et al. (2019) }\end{array}$ & $\begin{array}{l}\text { Grado de satisfacción } \\
\text { Formación práctica }\end{array}$ & $\begin{array}{c}\text { Validar un instrumento de evalua- } \\
\text { ción sobre la formación y el nivel } \\
\text { de satisfacción recibidos durante } \\
\text { el Practicum en estudiantes de } \\
\text { enfermería }\end{array}$ & $\begin{array}{l}\text { Estudio descrip- } \\
\text { tivo, transversal } \\
\text { de carácter } \\
\text { mixto }\end{array}$ & Cuestionario & Practicantes \\
\hline $\begin{array}{l}\text { Pascual y } \\
\text { Núñez (2012) }\end{array}$ & $\begin{array}{l}\text { Desempeño del } \\
\text { practicante } \\
\text { Competencias } \\
\text { Evaluación de } \\
\text { competencias }\end{array}$ & $\begin{array}{c}\text { Conocer las competencias que } \\
\text { han desarrollado los estudiantes } \\
\text { de psicopedagogía durante sus } \\
\text { prácticas externas }\end{array}$ & $\begin{array}{l}\text { Estudio de enfo- } \\
\text { que cualitativo }\end{array}$ & Encuesta & $\begin{array}{l}\text { Tutores de } \\
\text { práctica }\end{array}$ \\
\hline $\begin{array}{l}\text { Reyes, Valdez } \\
\text { y Moreno } \\
\text { (2012) }\end{array}$ & Evaluación practicante & $\begin{array}{l}\text { Exponer una experiencia de eva- } \\
\text { luación formativa sobre alumnos } \\
\text { en prácticas del magisterio }\end{array}$ & $\begin{array}{l}\text { Estudio de enfo- } \\
\text { que cualitativo }\end{array}$ & $\begin{array}{l}\text { Observación } \\
\text { Entrevista }\end{array}$ & $\begin{array}{c}33 \\
\text { estudiantes }\end{array}$ \\
\hline $\begin{array}{l}\text { Rivilla y } \\
\text { Domínguez } \\
\text { (2006) }\end{array}$ & Competencias & $\begin{array}{l}\text { Conocer los procesos formativos } \\
\text { desarrollados en la educación } \\
\text { presencial y a distancia en los } \\
\text { escenarios de práctica profesional }\end{array}$ & $\begin{array}{l}\text { Estudio de enfo- } \\
\text { que mixto }\end{array}$ & $\begin{array}{l}\text { Entrevista } \\
\text { Observación } \\
\text { Escala } \\
\text { Grupos de } \\
\text { discusión }\end{array}$ & $\begin{array}{l}\text { Estudiantes } \\
\text { Profesores }\end{array}$ \\
\hline $\begin{array}{l}\text { Rodicio y Igle- } \\
\text { sias (2011) }\end{array}$ & $\begin{array}{l}\text { Formación } \\
\text { Competencias } \\
\text { genéricas }\end{array}$ & $\begin{array}{l}\text { Diagnosticar las competencias } \\
\text { genéricas adquiridas a través } \\
\text { de Practicum en estudiantes de } \\
\text { educación en una universidad de } \\
\text { España }\end{array}$ & $\begin{array}{l}\text { Estudio de enfo- } \\
\text { que cuantitativo }\end{array}$ & Escala tipo Likert & $\begin{array}{c}52 \\
\text { estudiantes }\end{array}$ \\
\hline $\begin{array}{l}\text { Ruiz, Valdés, } \\
\text { y Castaño } \\
\text { (2006) }\end{array}$ & Carga de trabajo & $\begin{array}{l}\text { Estimar el tiempo invertido de los } \\
\text { estudiantes durante el Practicum }\end{array}$ & $\begin{array}{l}\text { Estudio de enfo- } \\
\text { que cuantitativo }\end{array}$ & Encuesta & $\begin{array}{c}15 \\
\text { estudiantes }\end{array}$ \\
\hline $\begin{array}{l}\text { Sepúlveda, } \\
\text { Gallardo, } \\
\text { y Mayorga } \\
\text { (2017) }\end{array}$ & $\begin{array}{l}\text { Evaluación } \\
\text { Grado de satisfacción }\end{array}$ & $\begin{array}{c}\text { Analizar el lugar que tienen los } \\
\text { procesos de evaluación del Prac- } \\
\text { ticum en una facultad de ciencias } \\
\text { de la educación. }\end{array}$ & $\begin{array}{l}\text { Estudio descrip- } \\
\text { tivo explicativo } \\
\text { de enfoque } \\
\text { cuantitativo }\end{array}$ & $\begin{array}{l}\text { Cuestionario tipo } \\
\text { escala Likert }\end{array}$ & $\begin{array}{c}261 \\
\text { estudiantes }\end{array}$ \\
\hline $\begin{array}{l}\text { Acevedo, } \\
\text { Becerra y Del- } \\
\text { gado (2014) }\end{array}$ & $\begin{array}{l}\text { Autopercepción } \\
\text { Competencias }\end{array}$ & $\begin{array}{l}\text { Identificar las autopercepciones } \\
\text { de un grupo de estudiantes de } \\
\text { psicología que se encuentran } \\
\text { realizando sus prácticas acerca } \\
\text { de las competencias que han } \\
\text { desarrollado }\end{array}$ & $\begin{array}{c}\text { Estudio } \\
\text { transversal } \\
\text { de enfoque } \\
\text { cuantitativo }\end{array}$ & $\begin{array}{c}\text { Cuestionario tipo } \\
\text { Likert }\end{array}$ & $\begin{array}{l}85 \text { estu- } \\
\text { diantes en } \\
\text { práctica }\end{array}$ \\
\hline $\begin{array}{l}\text { Arias, García } \\
\text { G. y Cardona } \\
\text { (2019) }\end{array}$ & $\begin{array}{l}\text { Competencia en } \\
\text { investigación }\end{array}$ & $\begin{array}{l}\text { Evaluar la apropiación de compe- } \\
\text { tencias de la investigación formati- } \\
\text { va en estudiantes de microbiolo- } \\
\text { gía que realizaron sus prácticas en } \\
\text { el 2009- } 2017\end{array}$ & $\begin{array}{l}\text { Estudio de enfo- } \\
\text { que cuantitativo }\end{array}$ & $\begin{array}{l}\text { Escala de medición } \\
\text { de competencias } \\
\text { relacionadas con } \\
\text { los procesos de } \\
\text { investigación } \\
\text { formativa. }\end{array}$ & $\begin{array}{l}369 \text { prac- } \\
\text { ticantes y } \\
\text { egresados }\end{array}$ \\
\hline $\begin{array}{l}\text { Castellanos, } \\
\text { Guarnizo y } \\
\text { Salamanca } \\
\text { (2011) }\end{array}$ & $\begin{array}{l}\text { Ansiedad } \\
\text { Estrategias de } \\
\text { afrontamiento }\end{array}$ & $\begin{array}{l}\text { Analizar las estrategias de } \\
\text { afrontamiento frente a los niveles } \\
\text { de ansiedad en estudiantes de } \\
\text { pedagogía y educación durante su } \\
\text { práctica profesional. }\end{array}$ & $\begin{array}{l}\text { Estudio no } \\
\text { experimental de } \\
\text { tipo correlacio- } \\
\text { nal de enfoque } \\
\text { cuantitativo }\end{array}$ & $\begin{array}{l}\text { Escala estrategias } \\
\text { de Coping de Cho- } \\
\text { rot y Sandini } \\
\text { Escala Zung de } \\
\quad \text { Zung }\end{array}$ & $\begin{array}{c}36 \\
\text { practicantes }\end{array}$ \\
\hline
\end{tabular}




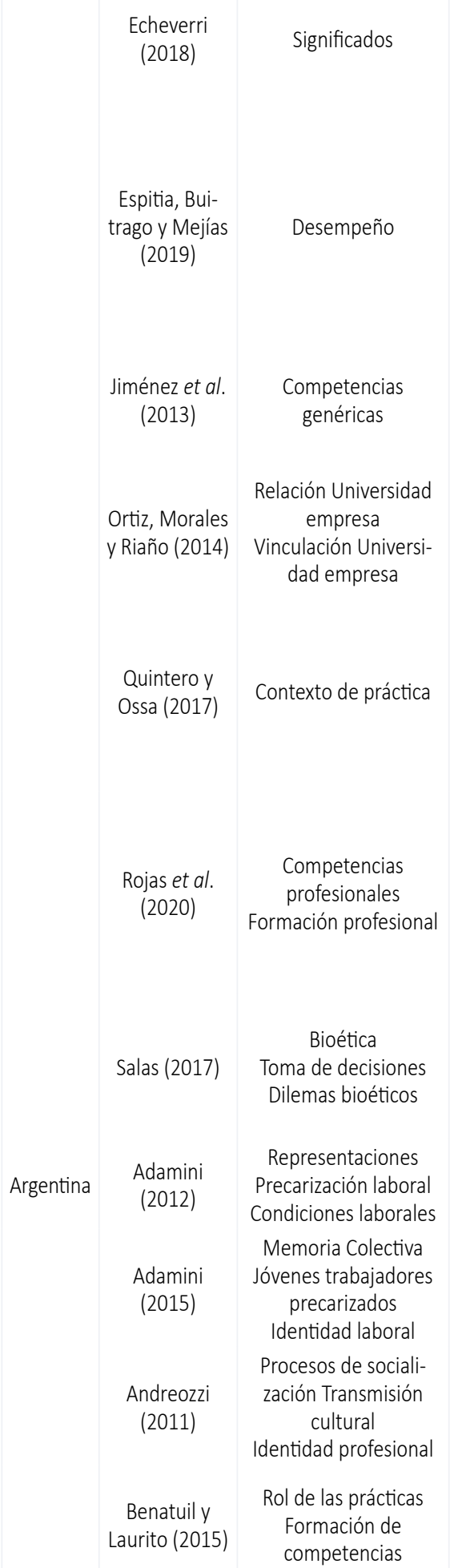

Comprender los significados sobre las prácticas profesionales en estudiantes de psicología de una universidad en Colombia.

Analizar los resultados de los procesos evaluativos de los estudiantes que realizaron pasantías como una modalidad de grado en un programa de ingeniería de la Universidad Militar de Nueva Granada

Identificar las competencias genéricas que se desarrollan comúnmente en todas las disciplinas y su nivel de aplicación durante las pasantías

Caracterizar las pasantías que realizan los estudiantes de la Universidad Militar de Nueva granada en el sector productivo

Caracterizar el contexto social de las prácticas profesionales en psicología realizadas por estudiantes de una universidad de Colombia

Analizar la percepción de las competencias desarrolladas por practicantes de tecnología en producción e ingeniería industrial.

Reconocer los dilemas bioéticos a los que se enfrentan un grupo de estudiantes de enfermería en los escenarios clínicos de su práctica profesional

Analizar las representaciones laborales de los pasantes con relación a su práctica

Analizar la incidencia de la memoria colectiva en las identidades laborales de jóvenes trabajadores precarizados

Socializar las ideas sobre las prácticas profesionales que tienen los estudiantes a través de sus relatos

Analizar el rol que tienen las prácticas profesionales con relación formación de competencias profesionales
Estudio de enfoque cualitativo

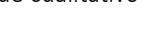

Estudio de enfoque cuantitativo Estudio exploratorio descriptivo de enfoque cuantitativo

Estudio de enfoque cualitativo

Estudio de carácter descriptivo de enfoque cuantitativo

Estudio descriptivo mixto no experimental transeccionalCorrelacional

Estudio de enfo-
que mixto

Estudio de enfoque cualitativo

Estudio de enfoque cualitativo

Estudio de carácter cualitativo

Estudio descriptivo de enfoque cuantitativo
Revisión documental de los relatos de practicantes contenidos en los proyectos de prácticas

335 proyectos elaborados por practicantes

Formato de evaluación de la pasantía 30 estudiantes

Encuesta diseñada

117

en escala Likert egresados

Revisión documen-

tal de informes

Entrevistas

Pasantes

semiestructuradas (n)

259 proyectos de prác-

Revisión documen- ticas y 259

tal de proyectos de informes prácticas finales elaborados por practicantes 32 practicantes Cuestionario en 22 coordimodalidad de nadores de escala Likert prácticas en las empresas 34 docentes

Encuesta

Entrevista

Observación participante

Docentes

Estudiantes Empleadores

Entrevista semiestructurada

Pasantes

Entrevista Egresados

Revisión documental de relatos de Estudiantes estudiantes

Encuesta 41 practicantes 
Castagno y

Fornasari

(2013)

Malet (2015)

Sáenz y

Pampalone

(2018)

entoni, Randazzo y Polini,

Arellano

México

y Santoyo

(2011)

De la Rosa

et al. (2017)

González,

Matus y Fernández (2017)

Jiménez et al.

Macías (2012)

Significados

Experiencias

Competencias

Márquez,

Morán y Pérez Vivencias pasantes

(2016)

Ramírez et al.

(2012)
Analizar acontecimientos que afectaron lo subjetivo e identitario a los estudiantes en práctica de psicología educativa de la Universidad de Córdoba.

Describir cómo son las prácticas profesionales supervisadas en un pregrado de ingeniería química.

Analizar la relación del plan de estudios con la formación académica y de competencias de los practicantes de psicología.

Evaluar los resultados obtenidos en la implementación de un programa de prácticas profesionales en sus primeros años en la carrera de bioquímica y su impacto en el desarrollo profesional de los egresados.

Socializar el proceso aplicación de enseñanza en la investigación, en el Practicum sociológico desde la supervisión y evaluación de sus etapas

Conocer la eficacia de un programa de práctica supervisada mediada por la tecnología con relación al desarrollo de competencias en el campo clínico en estudiantes de psicología.

Validar un instrumento de evaluación sobre los factores más importantes para una formación integra de pasantes

Analizar cómo contribuye la práctica en la formación profesional íntegra y de competencias en estudiantes de una facultad de pedagogía

Describir e interpretar el significado que el estudiante asigna las prácticas profesionales en la carrera de nutrición en una universidad de México,

Comprender cómo son las vivencias frente a la resolución de problemas clínicos en pasantes de enfermería.

Conocer las condiciones de trabajo en las que un grupo de pasantes de medicina realizó su servicio social
Estudio de enfoque cualitativo

Autobiografías Grupos Focales

33

practicantes

Egresados

Tutores

Estudio de enfo- Entrevistas

que Cualitativo semiestructuradas Instructores Personal de

RR. HH

Estudio de carácter descriptivo, transversal prospectivo de enfoque mixto

Revisión documental Entrevistas semiestructuradas

Estudiantes Docentes

Estudio de enfoque cuantitativo

Cuestionario en

188 pracmodalidad de ticantes escala Likert egresados

Estudio de enfoque cualitativo

Revisión documental Observación

Estudiantes durante el practicum

Estudio de diseño cuasi experimenta de enfoque cuantitativo

Estudio de enfoque cuantitativo

Estudio de carácter exploratorio con enfoque cuantitativo

Estudio interpretativo con enfoque cualitativo

Escala de terapia cognitiva- ETC de Practicantes Beck

Escala valorativa Estudiantes

Estudio descriptivo interpretativo de enfoque cualitativo

Estudio de carácter cuantitativo
Estudiantes

Encuesta

56

practicantes

Revisión

documental

Entrevista

Practicantes

Entrevista se-

miestructurada a 8 pasantes profundidad

Encuesta 262 pasantes semiestructurada 


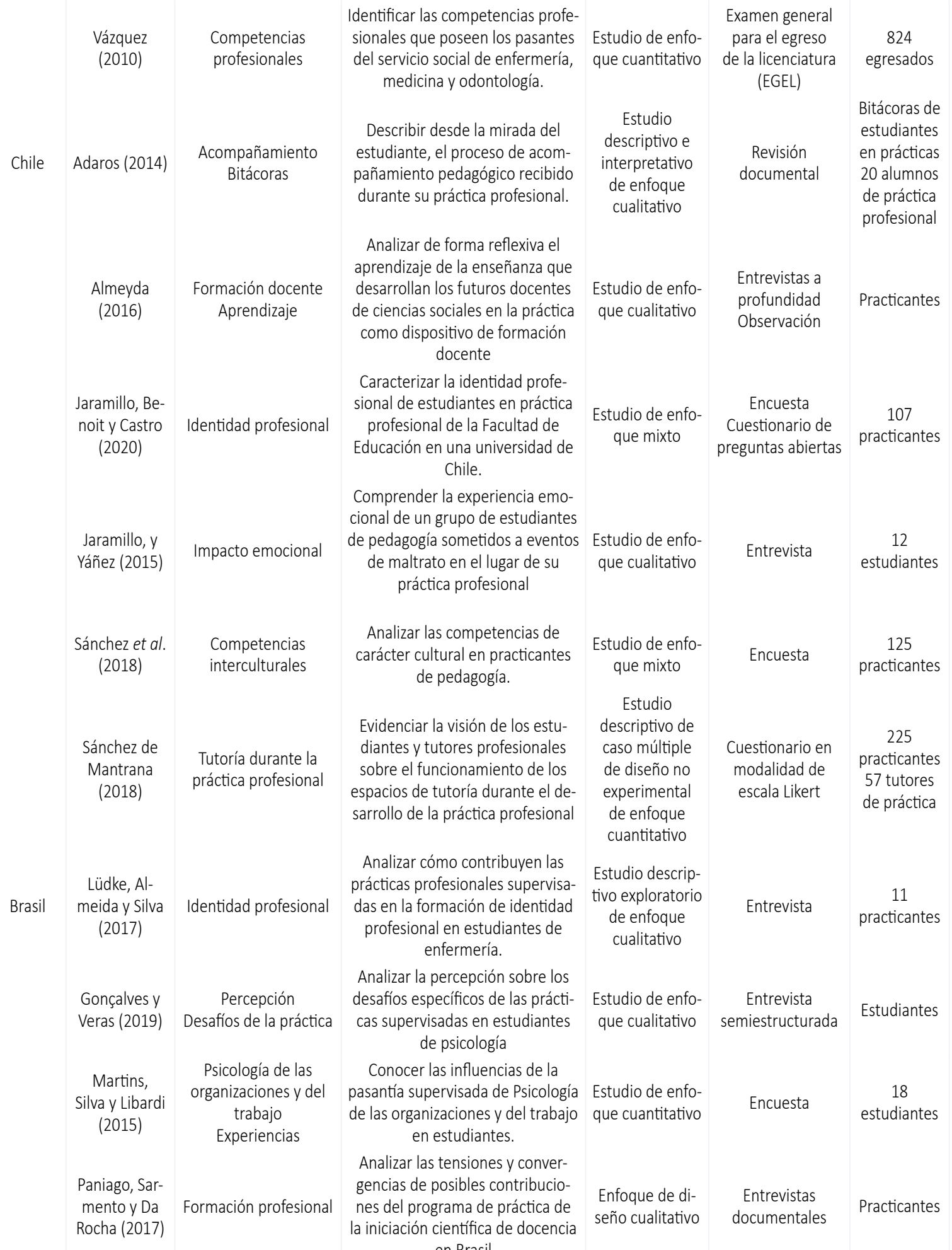

$$
\text { en Brasil }
$$




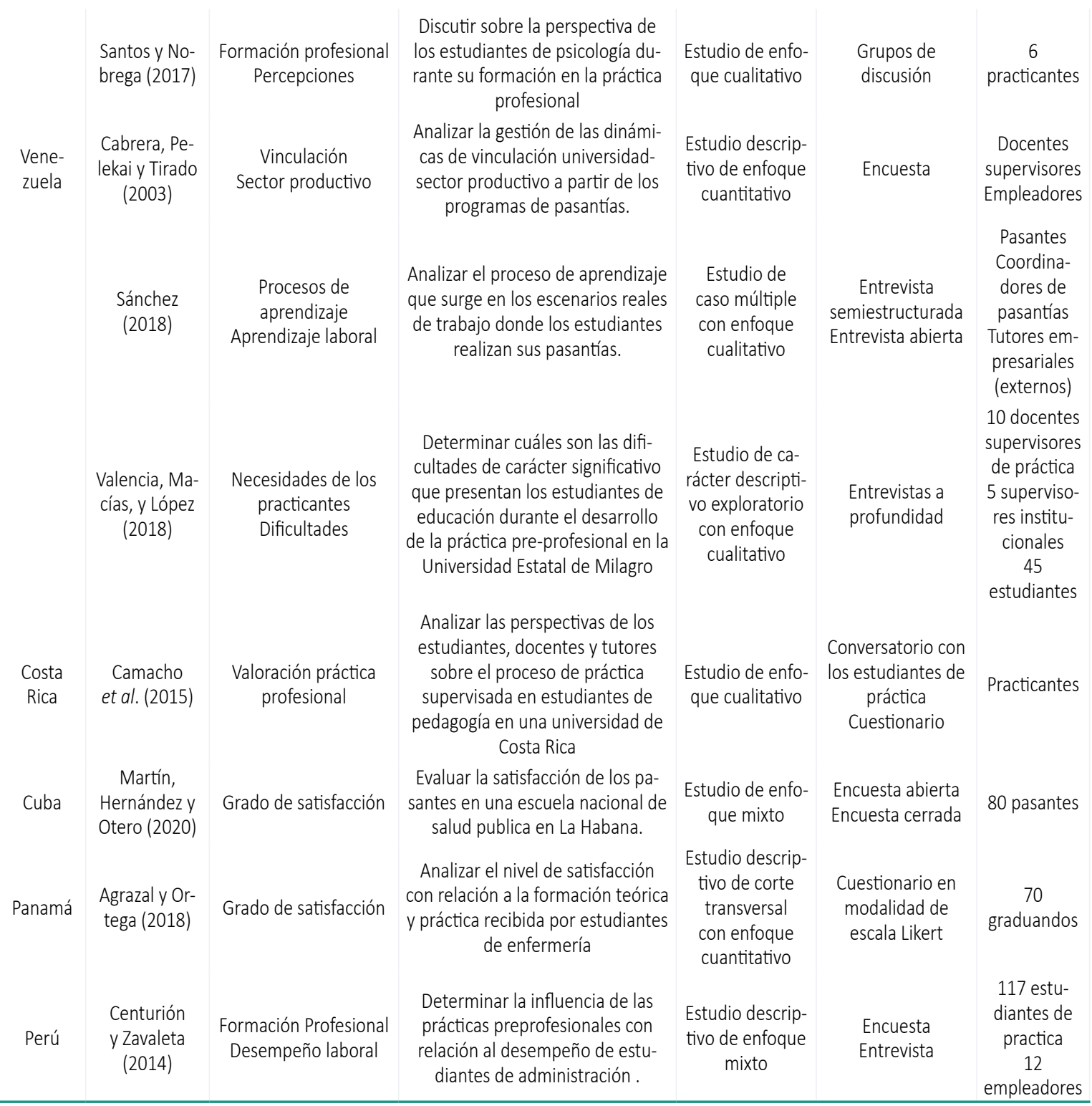

En síntesis, la consolidación de los estudios sobre las prácticas profesionales en el ámbito educativo e institucional están mediados y organizados por las demandas de contextos que van desde lo social, económico hasta lo cultural, en los que se originan y evolucionan, de esa manera, es posible delimitar y al mismo tiempo caracterizar la revisión en cuatro tendencias:

\subsection{Tendencia relacionada con el papel de las prácticas profesionales}

En torno a las prácticas profesionales y las diferentes temáticas estudiadas se encontró que un aspecto de actual relevancia es su papel en la inserción 
laboral relacionado con: contexto, representaciones, condiciones, salud mental, precarización laboral. Este proceso, es articulado con empleabilidad y permanencia laboral, para los egresados (Hervás et al., 2012; Tentoni, Radazzo y Polini, 2012), en sectores públicos, privados, investigación, en ámbitos de reconocimiento internacional. Otros aspectos abordados son; las condiciones físicas donde se realizan las prácticas profesionales (Blanco et al., 2012), contextos como empresas, entidades gubernamentales, fundaciones que han representado una variedad de demandas o necesidades de la comunidad, lo que implica una formación que supere lo teórico, prácticas contextualizadas con la realidad social, articuladas a las características de la comunidad (Quintero y Henao, 2017). El papel de los tutores o supervisores al dar a conocer el contexto, interactuar con la comunidad e incluso aumentar el nivel de interés por mejorar la calidad de su desempeño. Otro elemento relevante, es que la inserción laboral se entrelazó con salud mental de los practicantes y su estado emocional como la ansiedad, estrategias de afrontamiento que ayuden a su reducción, y alteraciones a nivel emocional por exigencia del entorno, al encuentro con lo desconocido al inicio de la práctica profesional (Castellanos, Guarnizo y Salamanca, 2011). Este nuevo escenario, generó otro tema de investigación, los practicantes que enfrentaron experiencias de maltrato, amenazas en los sitios de práctica por parte de personas figuras de autoridad, produciendo sensación de frustración hacia la carrera (Jaramillo y Yáñez, 2015). Estos estudios plantean elementos relevantes de las prácticas como mecanismo de inserción laboral, pero es el nivel subjetivo que suscitan repercusiones de orden emotivo relacionadas con el bienestar del practicante, su salud mental que puede ser afectada por eventos como el maltrato psicológico y no solo las condiciones monetarias y de vinculación óptimas contribuyen a la inserción laboral.

En algunos estudios las prácticas son un mecanismo de transición hacia el mundo laboral, pero también, una etapa de precarización laboral, de desprotección e inestabilidad, desarticulación entre aprendizajes recibidos en el aula de clase con lo asignado por la organización, considerando que es un proceso netamente instrumental, afectando la idea de pensarse una inserción laboral como proceso de carácter favorable (Adamini, 2012; 2015). Por lo tanto, desde las condiciones laborales se presentaron aspectos poco favorables como el sostenimiento insuficiente, que es asumido por los familiares del practicante, intensivas horas de dedicación, alimentación descuidada, además capacidad mínima para proteger a los pasantes y un reducido apoyo institucional (Ramírez et al., 2012). 
Asociado a la inserción laboral, también se relacionó las prácticas profesionales o pasantía con temas como: el aprendizaje laboral en escenarios de trabajo reales que posibilitan el desarrollo de competencias requeridas para ser empleable, incorporar el aprendizaje experiencial, social y culturalmente mediado de interacciones e intercambios que trascienden lo individual (Sánchez, 2018) permite la integración de conocimiento por medio de la interacción social (Ramírez, 2014; Almeyda, 2016), al igual que con el desempeño laboral al momento del egreso (Centurión y Zavaleta, 2013).

\subsection{Tendencia relacionada con recursos estructurales y de socialización}

En este sentido de los temas más relacionados en los estudios fue la identidad, a partir de procesos de socialización y transmisión cultural. Surge una necesidad de trabajar en la imagen que se proyecta (Andreozzi, 2011). Como acontecimiento significativo, de articulación de lo vivido y aprendido en las aulas con las expectativas a nivel profesional. Estudiar la identidad permite la comprensión de lo que es la aproximación hacia el futuro profesional (Castagno y Fornasari, 2013). Permite al practicante desde el primer ambiente de trabajo, la construcción, interpretación y comprensión del rol que tiene su profesión, y se construyen otras identidades que son permeada por estas dinámicas, la de supervisores o docentes (Lüdke, Almeida y Silva, 2017). De igual manera, la valoración asignada por el practicante a su proceso formativo, el carácter dinámico y complejo de niveles de subjetividad personal y social otros de los aspectos que se abordaron (Jaramillo, Benoit y Castro, 2019).

El estudio de la percepción, relacionado con los desafíos en los sitios de práctica, la curiosidad, el rol institucional y donde la asignación de tareas fue muy diferentes a la esperada. Otro interés, las expectativas sobre lo que se va a aportar como practicante a los sitios de prácticas, en contraste con la oportunidad de insertarse en diversos contextos, aunque se presenten dificultades en cuanto a la inserción en el campo (González, Martín y González, 2019; Gonçalves y Veras, 2019; Santos y Nóbrega, 2017). Frente a la expectativa de formación profesional, por parte de los estudiantes, hay una valoración de mayor nivel en cuanto a las competencias (Rojas et al., 2020) y los significados que se construyeron frente a la práctica profesional (Echeverri, 2018). Este primer acercamiento al mundo laboral genera impacto emocional y aprendizaje para manejar sus afectos y los escenarios de práctica posibilitan que se incorpore. 
La formación profesional integral con el contexto productivo. Se reconoce que las prácticas profesionales supervisadas o externa permite contextualizarse con el futuro profesional lo que requiere tener claro la estructuración del proceso en cuanto a: asuntos administrativos, asignación horaria, el acompañamiento por parte de los supervisores y relaciones humanas del personal con los que se ven involucrados, al igual que una buena gestión al momento de elegir las instituciones o centros de práctica (Camacho et al., 2015; Mayorga et al., 2017; Agrazal y Ortega, 2018; Mayorga et al., 2017).

La supervisión y acompañamiento de los espacios, la retroalimentación por parte de los tutores, la comprensión al momento de asesorar, las sugerencias para mejorar el desempeño, el fomento de estrategias de autoevaluación, el acompañamiento para la gestión de emociones, hacen que el papel del tutor resulte fundamental para el tránsito del estudiante que se proyecta como profesional. Este acompañamiento pedagógico permite situarse, conocer la profesión, poner a prueba y reconocer habilidades, incorporar modelos de aprendizaje (Adaros, 2014). Otros reportes de investigación abordaron la satisfacción de las expectativas sobre los profesores y su rol, la calidad de los medios de enseñanza, material de trabajo, las metodologías utilizadas, estructuras físicas y el acceso al internet (Martín, Hernández y Otero, 2020), la duración del Practicum, el trabajo colaborativo, el nivel de conocimientos previos al Practicum, la organización de las sesiones (Montejano et al., 2019).

Entre los abordajes en los estudios se destaca lo relacionado con la formación integral, desde la estructura de la práctica, el proceso y resultados al final de esta, la satisfacción y la utilidad percibida por parte de los estudiantes durante la práctica profesional (González, Matus y Fernández, 2017).

\subsection{Tendencia relacionada con la vinculación entre formación y mercado de trabajo}

En este ámbito la formación es asociada a la calidad desde factores como, la selección de centros de prácticas, que cuenten con profesionales orientadores adecuados, claras funciones para los practicantes, es interacción de la formación con el mundo laboral. Otras miradas asocian la formación con competencias laborales, profesionales, genérica y específicas, habilidades y actitudes adquiridas de las necesidades, las problemáticas reales y desarrollo de hábitos dentro de los propios centros de trabajo (Rojas et al., 2020; Benatuil y Laurito, 2015; Jiménez et al., 2014; Rodicio y Iglesias, 2011). En menor predomino algunos estudios reconocieron las competencias de investigación, creatividad, interculturales de los practicantes en contextos de 
diversidad cultural, para incorporar en los contenidos de su práctica (Arias, García y Arias, 2019; Sánchez et al., 2018). Las competencias de tipo transversal, y otras como las de tipo administrativo, comunicativo, motivacionales, y creativas son valoradas en un nivel favorable por los estudiantes y empleadores. (Mareque, Prada y Pino, 2018).

\subsection{Tendencia relacionada con la vinculación universidad y sector empresarial}

Esta temática se relacionó con la gestión, encontrando que las empresas no tienen políticas claras y actualizadas para articularse con instituciones de educación superior que beneficien a los estudiantes, y por el lado del sector de educación no se contaba con políticas institucionales claras para la vinculación con las empresas, con el personal y recursos que les permitiera atender a las demandas del sector productivo (Cabrera, Pelekais y Tirado, 2003). Sin embargo, los vínculos de las universidades con escenarios empresariales han permitido que se aprenda sobre cómo funciona el sector empresarial (Ortiz, Morales-Rubiano y Riaño, 2014).

\section{DISCUSIÓN}

La revisión sistemática realizada permitió identificar y caracterizar las tendencias de investigación sobre las prácticas profesionales como la relacionada con vinculación entre formación profesional y el mercado de trabajo, donde la comprensión de la aplicación profesional surge a partir de investigar aspectos interdependientes como: el currículo, los significados, las características de los docentes supervisores, la cooperación interinstitucional, como también las competencias desarrolladas en el contexto de las prácticas profesionales (Benatuil y Laurito, 2015; Echeverri, 2018).

En los estudios enmarcados en la tendencia relacionada con el papel de las prácticas profesionales, se reveló que este proceso se constituye para la educación superior en la manera de favorecer la transición a la inserción laboral, sin embargo, está condicionado por la evolución de las demandas, desafíos y cambios políticos que imponen no solo ajustes a los procesos relativos a la formación profesional, sino también a la relación con el trabajo. De ese modo los intereses de la formación profesional se ven superados por las transformaciones del mundo del trabajo que avanzan bajo la flexibilidad laboral, entendida e implementada en términos de desregulación del mercado laboral y de intensificación y precarización del trabajo (De la Garza, 2000), condiciones que enfrentan las prácticas profesionales (Adamini, 2012), 
teniendo un impacto sobre las subjetividades de los jóvenes y a su vez el trabajo pierde centralidad en su vida (Antunes, 2000; 2005).

En la tendencia relacionada con recursos estructurales y de socialización, las investigaciones destacan abordajes sobre la construcción de identidad (Andreozzi, 2011; Castagno y Fornasari, 2013; Lüdke, Almeida y Silva, 2017; Jaramillo, Benoit y Castro, 2019), donde es evidente el progreso de la institucionalización como un elemento determinante en la relación sujeto y organización, ajuste-persona y de adaptación persona-organización (López, 2012), en el cual el conocimiento y las prácticas transcurren solo dentro del sistema como producción y reproducción social (Bourdieu, 2011).

Los estudios enmarcados en la tendencia relacionada con la vinculación universidad y sector empresarial evidencian la importancia de las prácticas que trasciende la relación universidad-empresa a la integración con el entorno sociocultural, económico, laboral y político (Hervás et al., 2012; Tentoni, Radazzo y Polini, 2012; Blanco et al., 2012; Quintero y Henao, 2017). Las competencias, la empleabilidad e inserción laboral, no se garantiza tanto por las habilidades formativas, por las cualidades demandadas sino, por los contactos personales, condiciones sociales y económicas con las que se cuentan (Orejuela et al., 2013), lo que implica reconocer la coexistencia entre las exigencias del mercado laboral en y diferentes ámbitos (políticos, económicos, culturales) como un complejo sistema social que influye sobre la vida social y la actuación del sujeto para enfrentarlo (Delgado, 2018).

Con respecto al diseño de investigación en los artículos revisados, predomina estudios de tipo cuantitativo como por ejemplo en temas de Competencias (Jiménez et al., 2014; Benatuil y Laurito, 2015), inserción laboral (Tentoni, Radazzo y Polini, 2012; González Matus y Fernández, 2017), con grado de satisfacción (Agrazal y Ortega, 2018; Mayorga et al., 2017) frente al cualitativo, sobre significados (Echeverri, 2018), precarización laboral (Adamini, 2012; Castagno y Fornasari, 2013) e identidad profesional (Andreozzi, 2011) y siendo los mixtos de menor recurrencia. Otro aspecto presente en los estudios es el énfasis del recurso teórico-metodológico, el discurso a través de entrevistas semiestructuradas (Sánchez, 2018; Márquez, Morán y Pérez, 2016), autobiografías, grupos focales (Castagno y Fornasari, 2013) entrevistas en profundidad (Valencia, Macías, y López, 2018), grupos de discusión (Santos y Nobrega, 2017) y conversatorio con los estudiantes (Camacho et al., 2015) como evidencia de su contribución a la producción de formas de conocimiento, disciplina y subjetivación laboral, acorde con los reque- 
rimientos de la empresa, capitalismo, procesos de precarización, desregulación, desigualdad y mercantilización del conocimiento.

A pesar de las diferentes denominaciones del concepto de práctica profesional y pasantía (Práctica profesional, Prácticas profesionales, Pasantía, Pasantías, Práctica preprofesional, prácticas externas, Practicum, Práctica supervisada, Prácticas supervisada), siendo difícil una definición universal, debido a que dependen del país y legislación que los regula (Rueda, 2014) y entidades como los sistemas de acreditación nacional (Tentoni, Radazzo y Polini, 2012) que establecen la relación, educación superior-universidad-empresa y Estado; en todos los casos se considera un proceso de transición al mundo laboral.

\section{CONCLUSIONES}

En conclusión, en la revisión realizada sobre las prácticas, se encuentran estudios del nivel social, individual y cotidiano, del nivel institucional y colectivo evidenciando acciones que garantizan la reproducción de la fuerza de trabajo, entre las normas que regulan dichas acciones (De la Garza, 2000). A demás, se destaca la ausencia de estudios que indaguen de una manera más profunda acerca del nivel más amplio de la sociedad como un complejo de estructuras diversas en cuanto a lo político, económico y cultural, sobre determinaciones macrosociales de las acciones individuales y colectiva, como el adelantado por Rueda (2014), sobre las prácticas como mecanismo eficiente para la transición de la escuela al trabajo comparando diferentes legislaciones partir de iniciativas propuestas por entidades que son autoridades a nivel mundial.

Por último, para la psicología organizacional y del trabajo- POT, campo que se interesa por la(s) relación(es) persona-trabajo(s)-organización(es), las prácticas profesionales en educación superior son relevantes como objeto de estudio en la medida que se trascienda en la investigación para fortalecer la comprensión sobre sus objetivos y retos en el ámbito de las grandes transformaciones de los contextos sociolaborales como resultado de la modernización neoliberal, las nuevas estructuras en las formas de producción, la flexibilización laboral, los cambios en la cultura y los impactos sobre las formas de aplicación de las prácticas dispuestas por las políticas de carácter económico y los cambios tecnológicos.

Conflicto de interés: No existe conflicto de interés en la ejecución y publicación de este estudio. 
Agradecimiento: Universidad del Valle.

Financiamiento: Universidad del Valle.

\section{REFERENCIAS}

Acevedo-Villamizar, G., Becerra-Álvarez, D. R., y Delgado-Martínez, A. C. (2014). Autopercepción de estudiantes de psicología sobre sus competencias en los campos, laboral, educativo y salud. Revista de estudios y experiencias en educación, 13, 151-168. https://www.redalyc.org/pdf/2431/243132847009.pdf

Adamini, M. (2012). La zona gris de las pasantías: entre el trabajo y la formación. Revista electrónica gestión de las personas y tecnología, 5(13), https://www. redalyc.org/pdf/4778/477847114006.pdf

Adamini, M. (2015). Memoria colectiva en las identificaciones laborales del presente: Un estudio a partir del caso de jóvenes trabajadores precarizados. Sociohistórica. Cuadernos del CISH, (35), http://www.sociohistorica.fahce.unlp.edu.ar/article/ view/SH2015n35a01

Adaros-Rojas, M. (2014). Acompañamiento pedagógico recibido por alumnos de pedagogía a través de las bitácoras en el contexto de la práctica profesional. REXE. Revista de estudios y experiencias en educación, 13(26), 91-116. https:// www.redalyc.org/articulo.oa?id=243132847006

Agrazal-García, J., y Ortega, B. (2018). Satisfacción de estudiantes de enfermería con su formación teórico-práctica. Universidad de Panamá, Sede Azuero. Enfermería Universitaria, 15(3), 265-273. https://doi.org/10.22201/ eneo.23958421e.2018.3.65993

Aguilar, M, C., y Rentería, E. (2017). Caracterización de la empleabilidad de los egresados de una institución de educación superior, a la luz del modelo Forrier y Sels. En E. Rentería, y S. Malvezzi., (eds). Temas e investigaciones en psicología Organizacional y del trabajo. (pp.141-161). Universidad del Valle.

Alcover, C. M. (2003). Las organizaciones en las sociedades actuales. En F. Gil y C.M. Alcover (Coords), Introducción a la psicología de las organizaciones. (pp.33-60). Alianza.

Almeyda-Hidalgo, L. (2016). Arrojados en la acción: Aprender a enseñar en la experiencia de práctica profesional. Estudios Pedagógicos (Valdivia), 42(4), 11-30. https://doi.org/10.4067/S0718-07052016000500002

Andreozzi, M. (2011). Las prácticas profesionales de formación como experiencias de pasaje y tránsito identitario. Archivos de Ciencias de la Educación, 5, 99-115. http://dialnet.unirioja.es/servlet/articulo?codigo $=4151106$

Antunes, R. (2000). La centralidad del trabajo hoy. Papeles de Población, 6(25), http://www.redalyc.org/articulo.oa?id=11202505

Antunes, R. (2005). Los sentidos del trabajo: ensayo sobre la afirmación y la negación del trabajo. Taller de estudios laborales

Arellano-Sánchez, J. R., y Santoyo-Rodríguez, M. (2011). La supervisión y la evaluación del Practicum como elemento fundamental para la realización de buenas prácticas profesionales en alumnos de ciencias sociales. REDU. Revista de Docencia Universitaria, 9(2), 183. https://doi.org/10.4995/redu.2011.6167

Arias-Marín, L., García-Restrepo, G. del S., y Cardona-Arias, J. A. (2019). Impacto de las prácticas profesionales sobre las competencias de investigación formativa en estudiantes de Microbiología de la Universidad de Antioquia-Colombia. Revista Virtual Universidad Católica del Norte, 56, 2-15. https://www.redalyc.org/ articulo.oa?id=194259585002 
Ballesteros-Velázquez, B., Manzano-Soto, N., y Moriano, J. A. (2001). Seguimiento y evaluación en la UNED del sistema de prácticas de los alumnos en empresas. RELIEVE - Revista electrónica de investigación y evaluación educativa, 7(1), 3-21. https://doi.org/10.7203/relieve.7.1.4447

Barbosa-Chacón, J. W., Barbosa-Herrera, J. C., y Rodríguez-Villabona, M. (2013). Revisión y análisis documental para estado del arte: una propuesta metodológica desde el contexto de la sistematización de experiencias educativas. Investigación bibliotecológica, 27(61), 83-105. http://www.scielo.org.mx/scielo.php?scrip$\mathrm{t}=\mathrm{sci}$ _arttext\&pid=S0187-358X2013000300005\&lng=es\&tIng=es

Benatuil, D., y Laurito, J. (2015). The role of supervised Practicums in a sample of Psychology students from a private university in Argentina. PSIENCIA. Revista latinoamericana de ciencia psicológica, 7(2), 397-410. https://doi.org/10.5872/ psiencia/7.2.141

Blanco-Silva, F., López-Díaz, A., López del Corral M., Ó., y Paz-Penín, C. (2012). Las prácticas profesionales como herramienta de inserción laboral para ingenieros industriales: realización de auditorías de seguridad en las instalaciones. Revista de currículum y formación de profesorado, 16(1), 317-324. https://www.redalyc. org/articulo.oa? $i d=56724377018$ \&idp $=1$ \& $\mathrm{cid}=866$

Botero-Sarassa, J., Rentería-Pérez, E., y Malvezzi, S. (2020). Dinámicas contextuales, recursos individuales y empleabilidad: El caso del profesorado universitario. Psicoperspectivas, 19(1), 1-16. http://dx.doi.org/10.5027/psicoperspectivas-vol19-issue1-fulltext-1741

Bourdieu, P. (2011). Las estrategias de reproducción social (1st ed.). Siglo Veintiuno Editores S.A.

Braun, V., yClarke, V. (2006). Using thematic analysis in psychology. Qualitative Research in Psychology, 3(2), 77-101. https://doi.org/10.1191/1478088706qp063oa

Burguera-Condon, J., y Arias-Blanco, J. (2011). Los coordinadores de prácticas como supervisores del practicum. REDU. Revista de Docencia Universitaria, 9(3), 219-235. https://doi.org/10.4995/redu.2011.11227

Cabeza-González, M. C., Serrate-González, S., y Casillas-Martín, S. (2017). Valoración de los alumnos de la adquisición de competencias generales y específicas de las prácticas externas: Factores determinantes. Revista mexicana de investigación Educativa, 22(74), 685-704. http://www.scielo.org.mx/scielo.php?script=sci_ arttext\&pid=S1405-66662017000300685\&Ing=es\&tIng=es

Cabrera, F., De Pelekais, C., y Tirado, L. (2003). Gestión de vinculación entre los institutos universitarios tecnológicos y el sector productivo a través de los programas de pasantías industriales. Telos: Revista de estudios interdisciplinarios en ciencias sociales, 5(3), 394-407. http://ojs.urbe.edu/index.php/telos/article/ view/1148/1076

Camacho-Oviedo, M., Castillo-Cedeño, R., León-Arce, H., Miranda-Calderón, L. A., Pereira-Pérez, Z., y Vásquez-Salazar, E. (2015). La mirada estudiantil acerca del proceso de práctica supervisada en las carreras de Pedagogía de la Universidad Nacional. Revista electrónica Educare, 19(2). https://doi.org/10.15359/ree.192.23

Cámara-Estrella, Á. M., Abril- Gallego, A. M., Díaz-Pareja, E. M., Gutiérrez-García, F., Párraga-Montilla, J. A., Romero-Ariza, M., y Ortega-Tudela, J. M. (2011). Análisis de competencias en la formación de maestros a través del Practicum. REDU. Revista de docencia universitaria, 9(2), 55. https://doi.org/10.4995/redu.2011.6158

Campillo-Díaz, M., Sáez- Carreras, J., y del Cerro-Velázquez, F. (2012). El estudio de la práctica y la formación de los profesionales: un reto a las universidades. Revista de educación a distancia, (6). https://revistas.um.es/red/article/view/245151 
Casal, B. J. (1997). Modalidades de transición profesional, mercado de trabajo y condiciones de empleo. Cuadernos de relaciones laborales, 11, 19. https:// revistas.ucm.es/index.php/CRLA/article/view/CRLA9797220019A

Castagno, M., y Fornasari, M. (2013). Tres momentos del inicio de una vida profesional. Valor identitario de las prácticas universitarias. Revista Costarricense de Psicología, 32(2), 212-212. https://www.redalyc.org/pdf/4767/476748718006. pdf.

Castellanos-Cárdenas, M. T., Guarnizo-Castillo, C. A., y Salamanca-Camargo, Y. (2011). Relación entre niveles de ansiedad y estrategias de afrontamiento en practicantes de psicología de una universidad colombiana. International Journal of Psychological Research, 4(1), 50-57. https://www.redalyc.org/pdf/2990/299022819007. pdf.

Centurion-Medina, R., y Zavaleta-León, V. (2014). Prácticas pre profesionales en formación profesional para desempeño laboral de los estudiantes - administración, Uladech - Católica.in Crescendo, 5(2), 193-216. https://doi.org/10.21895/ incres.2014.v5n2.05

Congreso de la república de Colombia. (1994, 5 de febrero). Ley 115 por la cual se expide la ley general de educación. https://www.mineducacion.gov.co/1621/ articles-85906_archivo_pdf.pdf

De la Garza, E. (Coord.). (2000). Tratado latinoamericano de sociología del trabajo. Fondo de cultura económica

De la Rosa-Gómez, A., González-Pérez, M. A., Rueda-Trejo, J. A., y Rivera-Baños, J. (2017). La Práctica Supervisada Mediada por Tecnología como Escenario para la Enseñanza de Competencias Clínicas. Hamut'ay, 4(1), 75-84. https://doi. org/10.21503/hamu.v4i1.1396

Delgado, R. (2018). La práctica profesional como eje curricular de formación inicial universitaria: una metodología para su operacionalización. Investigación y postgrado, 33(1), 9-51. http://revistas.upel.digital/index.php/revinpost/article/ view/6801

Díaz, V. M (2002). Flexibilidad y educación superior en Colombia. Instituto Colombiano para el fomento y desarrollo de la educación superior, ICFES.

Echeverri-Gallo, C. (2018). Significados y contribuciones de las prácticas profesionales a la formación de pregrado en psicología. Avances en Psicología Latinoamericana, 36(3), 569-584. http://dx.doi.org/10.12804/revistas.urosario.edu.co/apl/a.5490

Espitia-Cubillos, A. A., Buitrago-Suescún, O. Y., y Mejías, A. (2019). Análisis del desempeño de los pasantes de Ingeniería Industrial de la Universidad Militar Nueva Granada en el periodo 2011-2015. Aletheia. Revista de Desarrollo Humano, Educativo y Social Contemporáneo, 11(2), 15-36. https://doi. org/10.11600/21450366.11.2aletheia.15.36

Fernández-Pérez, J. A. (2001). Elementos que consolidan el concepto profesión. Notas para su reflexión. REDIE. Revista Electrónica de Investigación Educativa. 3(11), 18. https://www.redalyc.org/pdf/155/15503202.pdf

Garrido, L. y Requena, M. (1996). La emancipación de los jóvenes en España. Ministerio de trabajo e inmigración (eds.). Injuve.

Gimeno, S. J. (1991). El Curriculum: una reflexión sobre la práctica. Morata.

Gonçalves, M. O., y Veras, R. M. (2019). Os desafios dos estágios supervisionados específicos em psicologia escolar Introdução. Arquivos Brasileiros de Psicologia, 71(1), 85-102. https://dx.doi.org/10.36482/1809-5267.ARBP2019v71i1p.85-102

González-Ramírez, P., Matus-Miranda, R., y Fernández-García, V. (2017). Factores determinantes en la formación de pasantes en servicio social. Construcción y 
validación de un instrumento. Enfermería Universitaria, 14(1), 3-9. https://doi. org/10.1016/j.reu.2016.10.003.

González-Serrate, S., Martín-Casillas, S., y González-Cabezas, M. (2019). Factores de calidad determinantes de la formación práctica de los estudiantes de educación. Ensaio, 27(105), 817-838. https://doi.org/10.1590/S0104-40362019002701625

Gough, D., Oliver, S., y Thomas, J. (2012). An introduction to systematic reviews. SAGE.

Hervás, A., Ayats, J. C., Desantes, R., y Juliá, J. F. (2012). Las prácticas en empresa como uno de los ejes vertebradores de la empleabilidad. Revista Iberoamericana de Educación Superior, 3(8), 3-33. https://doi.org/10.22201/ iisue.20072872e.2012.8.70

Jaramillo-Azema, C. A., Benoit-Ríos, C., y Castro-Cáceres, R. (2019). Identidad profesional de estudiantes de la Facultad de Educación en la Universidad Católica de la Santísima Concepción. Revista Educación, 44(1), 26. https://doi.org/10.15517/ revedu.v44i1.37678

Jaramillo-Sandoval, D. A., y Yáñez-Gallardo, R. (2015). Impacto emocional en estudiantes de pedagogía ante eventos de maltrato en la práctica profesional. Liberabit-Revista de Psicologia, 21(2), 245-252. https://www.redalyc.org/ pdf/686/68643124007.pdf

Jiménez-Jiménez, D. C., Fandiño-Cuca, F. A., Urrego-Montañéz, K. G., y Morales Rubiano, M. E. (2013). La contribución de las pasantías universitarias en el desarrollo de competencias profesionales en ciencias económicas. Revista Academia y Virtualidad, 5(1), 155-170. https://doi.org/https://doi.org/10.18359/ ravi. 2613

Jiménez-Yáñez, C. E., Martínez-Soto, Y., Rodríguez-Domínguez, N. A., y Padilla-Hacegaba, G. Y. (2014). Aprender a hacer: la importancia de las prácticas profesionales docentes. Educere, 18(61), 429-438. http://erevistas.saber.ula.ve/index. php/educere/article/view/12094

López, J. (2012). Bienestar laboral en profesionales de la medicina. La doble cara de la organización sanitaria: Factores saludables y de riesgo psicosocial. [Tesis doctoral, Universitat Autònoma de Barcelona]. Repositorio de documentos UAB. https://ddd.uab.cat/record/127617

Lüdke, M., Almeida, E. B., y Silva, A.L.B. (2017). Contribuciones de la Etapa Supervisada para la Formación de la Identidad Profesional de las enfermeras. Cultura de los Cuidados 21(48) http://dx.doi.org/10.14198/cuid.2017.48.15

Macías- Mozqueda, E. Y. (2012). Significado de las prácticas profesionales. La experiencia de un grupo de alumnos de nutrición de la Universidad Guadalajara Lamar. Revista Iberoamericana de Educación, 59(3), 1-10. https://doi. org/10.35362/rie5931378

Malet, A. M. (2015). Las prácticas profesionales supervisadas y el "acompañamiento", como relación pedagógica y formativa. Revista Argentina de Educación Superior, 7(10), 8-28. http://www.revistaraes.net/revistas/raes10_art1.pdf

Mareque-Álvarez-Santullano, M., de Prada-Creo, E., y Pino-Juste, M. (2018). Estudio sobre la capacidad técnica y las competencias transversales desarrolladas en las prácticas externas universitarias. Estudios Pedagógicos Valdivia, 44(3), 137-155. https://doi.org/10.4067/S0718-07052018000300137

Márquez-Martínez, G., Morán-Peña, L., y Pérez-Zumano, S. E. (2016). Vivencias de los pasantes de enfermería, en la resolución de problemas clínicos. Enfermería Universitaria, 13(1), 31-39. https://doi.org/10.1016/j.reu.2016.01.003

Martín, R. M. (2003). La inserción laboral de los universitarios a través de las prácticas en empresas. REIS 101(3) https://doi.org/10.2307/40184457 
Martínez, R. (2000). Aproximaciones teóricas a los procesos de inserción laboral. Revista del Ministerio de Trabajo y Asuntos Sociales, 26, 65-91. https://dialnet. unirioja.es/servlet/articulo?codigo $=193608$

Martín-Linares, X., Hernández-Meléndrez, D. E., y Otero-Ceballos, M. (2020). Satisfacción con la calidad de las pasantías en atención primaria de salud. Educación Médica Superior, 34(1), 1-11. http://scielo.sld.cu/scielo.php?script=sci_arttext\&pid=S0864-21412020000100010\&lng=es\&tlng=e

Martins-Silva, P., Silva-Junior, A, y Libardi de Oliveira, M.B.A. (2015). Psicologia organizacional e do trabalho: Relato de experiência em estágio supervisionado. Psicologia: Ciência e Profissão, 35(4), 1327-1339. https://dx.doi.org/10.1590/19823703000722014

Mayorga-Fernández, M. J., Sepúlveda-Ruiz, M. P., Madrid-Vivar, D., y Gallardo-Gil, M. (2017). Grado de satisfacción y utilidad profesional de las prácticas externas del alumnado de la Facultad de Ciencias de la Educación de la Universidad de Málaga (España). Perfiles Educativos, 39(157), 140-159. https://doi.org/10.22201/ iisue.24486167e.2017.157.58446

Montejano-Lozoya, R., Gea-Caballero, V., Miguel-Montoya, I., Juárez-Vela, R., SanjuánQuiles, Á., y Ferrer-Ferrandiz, E. (2019). Validation of a questionnaire designed to measure nursing student satisfaction with practical training. Revista Latinoamericana de Enfermagem, 27. https://doi.org/10.1590/1518-8345.3102.3206

Orejuela, J.; Bermúdez R. E., Urrea B. C., y Delgado L. (2013). Inserción laboral de jóvenes profesionales. El caso de los psicólogos bonaventurianos. Editorial Bonaventuriana. Universidad de San Buenaventura http://bibliotecadigital. usbcali.edu.co/bitstream/10819/4472/1/Insercion_laboral_jovenes_profesionales.pdf

Ortiz-Riaga, M. C., Morales-Rubiano, M. E., y Riaño-Triviño, A. (2014). Pasantías estudiantiles como estrategia de vinculación universidad entorno en la Universidad Militar Nueva Granada. Revista Educación y Desarrollo Social, 8(2), 128-145. https://doi.org/10.18359/reds.300

Paniago-Nogueira, R., Sarmento-Jacinto, T., y Da Rocha-Albuquerque, S. (2017). O Estágio Curricular Supervisionado e o Programa Brasileiro de Iniciação à Docência: Convergências, tensões e contributos. Revista Portuguesa de Educação, 30(2), 33. https://doi.org/10.21814/rpe.10228

Pascual-Gómez, I., y Núñez-del Río, M. C. (2012). La colaboración de los tutores de centros en la evaluación de competencias en el Prácticum. REOP - Revista Española de Orientación y Psicopedagogía, 23(3), 121. https://doi.org/10.5944/ reop.vol.23.num.3.2012.11467

Quintero-Jurado, J., y Ossa-Henao, Y. (2017). Caracterización del contexto social de las prácticas profesionales del programa de psicología de la Corporación Universitaria Minuto de Dios, Sede Bello, durante el año 2014. Un estudio de caso. Diálogos Sobre Educación. Temas Actuales en Investigación Educativa, 8(14), 1-15. https://doi.org/https://doi.org/10.32870/dse.v0i14.217

Ramírez de la Roche, O. F., Hamui-Sutton, A., Reynaga-Obregón, J., Varela Ruiz, M., Ponce de León, M. E., Villanueva, A., y Valverde Luna, I. (2012). Condiciones de trabajo de los médicos pasantes mexicanos durante el servicio social. Perfiles Educativos, 34(138), 92-107. https://www.redalyc.org/articulo. oa?id=13224551007

Ramírez Rivera, M. I. (2014). Pasantías internacionales en lenguas modernas: una valiosa experiencia en la formación docente. Educere, 18(61), 461-472. http:// erevistas.saber.ula.ve/index.php/educere/article/view/12097 
Rentería, E., (2007). Empleabilidad: Una lectura Psicosocial. Revista Colombiana de Estudios del Trabajo. https://www.researchgate.net/profile/Erico_Renteria2/ publication/264869527_EMPLEABILIDAD_UNA_LECTURA_PSICOOSOCIAL/ links/564291e508aeacfd89384080/EMPLEABILIDAD-UNA-LECTURA-PSICOSOCIAL.pdf

Rentería, E., (2008). Empleabilidad: versiones e implicaciones. Una lectura desde la psicología social. [Tesis de doctoral Faculdade de Psicologia Social y del Trabajo Universidad São Paulo].

Rentería Pérez, E. y Malvezzi, S. (2008). Empleabilidad, cambios y exigencias sociales en el trabajo. Universitas Psychologica, 7(2). https://revistas.javeriana.edu.co/ index.php/revPsycho/article/view/319

Reyes Ruiz-Gallardo, J., Valdés, A., y Moreno, C. (2012). Practicum y evaluación. Revista Electrónica Interuniversitaria de Formación del Profesorado, 15(3), 93-111. https://dialnet.unirioja.es/servlet/articulo?codigo=4615386

Rivilla-Medina, A., y Domínguez-Garrido, M. C. (2006). Los procesos de observación del prácticum: análisis de las competencias. Revista Española de Pedagogía, 64(233), 69-103. https://dialnet.unirioja.es/servlet/articulo?codigo=1973266

Rodicio-García, M. L., y Iglesias-Cortiza, M. (2011). La formación en competencias a través del Practicum : un estudio piloto. Revista de Educación, 354, 99-124. http://www.revistaeducacion.educacion.es/re354/re354_05.pdf

Rojas-Arenas, I. D., Vélez-Castañeda, C. K., Durango-Marín, J. A., Díaz Peláez, A., y Rodríguez Álvarez, A. F. (2020). Percepción del proceso de formación por competencias y su relación con las prácticas empresariales: un caso de estudio. Revista Virtual Universidad Católica del Norte, 60, 46-68. https://www.redalyc.org/ articulo.oa?id=1942/194263234004

Rueda-Rodríguez, A. E. (2014). Las prácticas profesionales y las pasantías desde la legislación comparada. Revista latinoamericana de derecho social, (19), 111-132. http://www.scielo.org.mx/scielo.php?script=sci_arttext\&pid=S1870-46702014000200111\&lng=es\&tlng=es

Ruiz-Gallardo, J., Valdés, A., y Castaño, S. (2006). Practicum y carga de trabajo. Revista de Investigación Educativa, 24(2), 557-574. https://revistas.um.es/rie/ article/view/97191

Sáenz, I., y Pampalone, L. (2018). Alcances y obstáculos de la práctica profesional supervisada en la formación del psicólogo. E-Universitas: UNR Journal, 1(21), 4-17. https://dialnet.unirioja.es/servlet/articulo?codigo=6937934

Salas, F. H. (2017). Dilemas bioéticos de los estudiantes de enfermería de la universidad surcolombiana en su práctica profesional. Revista Colombiana de Bioética 11(2), 62. https://doi.org/10.18270/rcb.v11i2.1994

Sánchez de Mantrana, M. (2018). El aprendizaje en contextos laborales reales: El caso de las pasantías de los estudiantes universitarios. Educere, 9(30), 345-357. http://erevistas.saber.ula.ve/index.php/educere/article/view/11855

Sánchez- Espinoza, E., Díaz-Araya, A., Mondaca-Rojas, C., y Mamani-Morales, J. C. (2018). Formación inicial docente, prácticas pedagógicas y competencias interculturales de los estudiantes de carreras de pedagogía de la universidad de Tarapacá, norte de Chile. Diálogo Andino - Revista de Historia, Geografía y Cultura Andina, 57, 21-38. http://dx.doi.org/10.4067/S0719-26812018000300021

Santos, A. C. dos, y Nóbrega, D. O. da. (2017). Dores e Delícias em ser Estagiária: o Estágio na Formação em Psicologia. Psicologia: Ciência e Profissão, 37(2), 515-528. https://doi.org/10.1590/1982-3703002992015

Sepúlveda-Ruiz, M. del P., Gallardo-Gil, M., Mayorga-Fernández, M. J., y MadridVivar, D. (2017). La evaluación del practicum: un proceso clave en la construcción 
y reconstrucción del pensamiento práctico. ENSAYOS. Revista de la Facultad de Educación de Albacete, 32(1), 93-110. https://dialnet.unirioja.es/servlet/articulo? codigo $=6535627$

Tentoni, J., Randazzo, V., y Polini, N. N. (2012). Práctica Profesional Bioquímica en la Universidad Nacional del Sur. Acta Bioquímica Clínica Latinoamericana, 46(4), 639-644. https://www.redalyc.org/articulo.oa?id=53525433006

Valencia-Medina, E. M., Macías-Alvarado, J., y López-Valencia, S. M. (2018). Las prácticas pre-profesionales en el contexto de la carrera de Licenciatura en Educación Inicial de la Universidad Estatal de Milagro. Revista Conrado, 14(63), 140-146. http://conrado.ucf.edu.cu/index.php/conrado

Vázquez-Martínez, F. D. (2010). Competencias profesionales de los pasantes de enfermería, medicina y odontología en servicio social en México. Revista Panamericana de Salud Pública, 28(4), 298-304. https://doi.org/10.1590/S102049892010001000009

Zabalza-Beraza, M. A. (2011). El Practicum en la formación universitaria: Estado del arte. Revista de educación. (354), 21-43. http://www.revistaeducacion.educacion. es/re354/re354_02.pdf. 